REPLY

\section{Autoimmune cardiac channelopathies: the heart of the matter}

\author{
Pietro Enea Lazzerini, Pier Leopoldo Capecchi, Franco Laghi-Pasini \\ and Mohamed Boutjdir
}

We thank Jin Li and Ange Maguy for their Correspondence (Autoimmune channelopathies: questions remain. Nat. Rev. Cardiol. http://dx.doi.org/10.1038/nrcardio.2017.110; 2017) ${ }^{1}$ on our Review (Lazzerini, P. E. et al. Autoimmune channelopathies as a novel mechanism in cardiac arrhythmias. Nat. Rev. Cardiol. http://dx.doi.org/10.1038/ nrcardio.2017.61;2017) $)^{2}$.

$\mathrm{Li}$ and Maguy state that the term "autoimmune cardiac channelopathies" was first introduced by Li et al. in 2013 (REF. 3). However, we were unable to identify the specific term "autoimmune cardiac channelopathies" in this article ${ }^{3}$. Conversely, the general term "autoimmune channelopathies" mentioned by Li et al. in their paper ${ }^{3}$ had been well recognized in the field of neuroscience since 2005 (REF. 4). In addition, searches on Google Scholar, PubMed, and
Scopus indicate that the specific term "autoimmune cardiac channelopathies" had not been used before our Review article in Nature Reviews Cardiology $y^{2}$.

We do not believe that the Figures in our Review are misleading or overemphasize the knowledge in the field. We agree that the use of whole sera containing anti-KCNQ1 autoantibodies $^{3}$ or anti- $\mathrm{Na}_{\mathrm{v}} 1.5$ autoantibodies $^{5}$ to demonstrate interaction with $I_{\mathrm{Ks}}$ and $I_{\mathrm{Na}}$, respectively, is not evidence of direct causality in the absence of the use of affinitypurified antibodies. Nevertheless, control sera negative for anti-KCNQ1 autoantibodies and anti- $\mathrm{Na}_{\mathrm{v}} 1.5$ autoantibodies was used and showed no electrophysiological effect on $I_{\mathrm{Ks}}$ or $I_{\mathrm{Na}}$, respectively, in these studies $^{3,5}$. Our use of schematic representations of autoantibodies acting on ion channels is intended to communicate the proposed mechanism of action simply. We hope that our Reply addresses the concerns about misunderstanding expressed by Li and Maguy.

Pietro Enea Lazzerini, Pier Leopoldo Capecchi and Franco Laghi-Pasini are at the Department of Medical Sciences, Surgery and Neurosciences, University of Siena, Viale Bracci 16, Siena, 53100, Italy.

Mohamed Boutjdir is at the VA New York Harbor Healthcare System, 800 Poly Place, Brooklyn, New York 11209, USA; at the SUNY Downstate Medical Center, 450 Clarkson Avenue, Brooklyn, New York 11203, USA; and at the NYU School of Medicine, 500 1st Avenue, New York, New York 10016, USA. Correspondence to P.E.L. lazzerini7@unisi.it

$\frac{\text { doi: } 10.1038 / \text { nrcardio } 2017.111}{\text { Published online } 20 \text { Jul } 2017}$

1. Li, J. \& Maguy, A. Autoimmune channelopathies: questions remain. Nat. Rev. Cardiol. http://dx.doi.org/ 10.1038/nrcardio.2017.110 (2017).

2. Lazzerini, P. E., Capecchi, P. L., Laghi-Pasini, F. $\&$ Boutjdir, M. Autoimmune channelopathies as a novel mechanism in cardiac arrhythmias. Nat. Rev. Cardiol. http://dx.doi.org/10.1038/nrcardio.2017.61 (2017).

3. $\mathrm{Li}$, J. et al. Anti-KCNQ1 $\mathrm{K}^{+}$channel autoantibodies increase $I_{\mathrm{Ks}}$ current and are associated with QT interval shortening in dilated cardiomyopathy. Cardiovasc. Res. 98, 496-503 (2013).

4. Buckley, C. \& Vincent, A. Autoimmune channelopathies. Nat. Clin. Pract. Neurol. 1, 22-33 (2005).

5. Korkmaz, S. et al. Provocation of an autoimmune response to cardiac voltage-gated sodium channel $\mathrm{Na}_{\mathrm{v}} 1.5$ induces cardiac conduction defects in rats. J. Am. Coll. Cardiol. 62, 340-349 (2013).

Competing interests statement

The authors declare no competing interests. 